Send your letters to the editor, British Dental

Journal, 64 Wimpole Street, London W1G 8YS

E-mail bdj@bda.org

Priority will be given to letters less than 500

words long. Authors must sign the letter,

which may be edited for reasons of space

\section{An easy ride?}

Sir,- As a busy practitioner I eagerly awaited the $B D J /$ Eastman CPD programme.

To gain 48 hours of verifiable CPD from the comfort of my armchair seemed too good to be true. Having a few minutes to spare between patients, I opened the journal from the back, reaching the questions before the papers.

Then scanning the relevant papers, in the fashion of a free entry competition I found all the answers in less than three minutes.

At this rate I should be able to get my whole years CPD hours by coffee. If CPD is to be taken seriously then surely we can't notch up hours this easily.

\section{Storrar}

\section{Gloucestershire}

The Editor responds: I would like to thank Dr Storrar for his comment. I agree with him that the whole issue of CPD is open to abuse, whatever format is used.

Dr Storrar's suggestion that people can just look up the answers in three minutes and thereby gain 60 minutes of verifiable CPD is obviously true, but hardly a responsible one. It is just as possible to go to a lecture, sneak out the back and still claim for CPD as long as someone thinks you were there.

However I believe the spirit of CPD is the complete reverse of Dr Storrar's suggestion. CPD was designed to demonstrate that the profession can maintain lifelong learning, and that the members of the profession are responsible, professional people who take this seriously.

We assume that people will choose topics that are genuinely helpful for their learning and development (rather than topics they already know about) and spend time reading, learning and reflecting.

Those people who take this approach to CPD should be both recognised and rewarded by being able to gain an appropriate time credit, and this is what we have tried to do with the BDJ/Eastman approach to CPD.

Of course it can be abused, as Dr Storrar has clearly stated. Will it be abused and by how many?

I don't know the answer to that, but the $B D J$ hopes that dentists will behave appropriately, professionally and ethically in their approach to CPD. After all, if we are to continue to call ourselves a profession that regulates itself then we should behave like one.

doi: 10.1038/sj.bdj.4810502

\section{NVOs}

Sir,-How many GDPs know about this NVQ? How many care about it? How many are involved in it? We should all know and care about it. I think the introduction of the NVQ is good.

Unfortunately, in my view the Record of Assessment handbook is abysmal. I understand that the GDC has tasked Skills for Health with looking at the problems with the NVQ.

May I strongly urge those of our colleagues who are in some way involved with the NVQ and are unhappy with it, to write to Skills for Health with their views, that is the only way change is likely to be brought about.

\section{J. F. Aitken}

By e-mail

doi: $10.1038 /$ sj.bdj.4810503

\section{Trend setting}

Sir,- We note with interest J. Pedlar's recent letter (BDJ 2003; 195: 119) in which he reports on seven patients with prolonged paraesthesia following articaine administration ${ }^{1}$. It would be of interest to know the duration of the paraesthesia, the number of patients with permanent symptoms, the distribution of the paraesthesia and the length of time over which the cases accrued.

Since the publication of our letter ${ }^{2}$ five further cases of lingual paraesthesia lasting longer than two weeks have come to our attention, and a further six cases have come to our attention from another region.

Furthermore two patients with prolonged lingual paraesthesia following articaine administration are exploring the medico-legal route. The Canadian experience, which reported an increase in post-operative paraesthesia following the introduction of articaine in the country ${ }^{3}$, appears to be mirrored in the United Kingdom.

The large number of patients reported in Mr. Pedlar's letter and the steady increase in patients with post-operative paraesthesia following articaine use in our region is certainly cause for concern. It would be useful to know if this is a general trend nationally.

\section{S. P. van Eeden}

\section{F. Patel}

Oxford

doi: $10.1038 /$ sj.bdj.4810504

I. Pedlar J. Prolonged paraesthesia. BDJ 2003; 194: 181

2. van Beden S P., Patel M F. Prolonged paraesthesia following inferior alveolar nerve block using articaine. Br J Oral Maxillofac Surg 2002; 40: 519-520.

3. Haas D A, Lennon D. A 21 year retrospective study of reports of paraesthesia following local anaesthetic administration. J Can Dent Assoc 1995; 319-330.

\section{Food and drink}

Sir,- On my recent visit to London I heard a speaker on the American Neoconservatives from the London School of Economics.

He was asked if he believed there really was an Axis of Evil and his answer had potentially important oral implications. He replied yes, and that it consisted of British food and cheap French wine in the post-World War II era!

J. P. Brown

Texas

doi: 10.1038/sj.bdj.4810505

\section{Giving good advice?}

Sir,- I was recently asked for guidance by a senior student at a well-known and highly regarded school who was considering dental surgery for his chosen career.

Understandably, he wished to be advised by someone whose experience in the profession he could rely upon before proceeding with a step that would affect his entire life.

Having willingly agreed to spend some time explaining the nature of our 
profession to him and the scope of the responsibilities involved, I felt that it would be sensible to have at hand some printed materials that he could take away from our meeting and read at his leisure.

I had on earlier occasions asked the General Dental Council for their publications on guidance for prospective entrants to the profession, but I was shocked this time to be told that they no longer supplied anything other than the addresses of University Dental Schools!

Members of a profession whose governing body is so apathetic have good cause to feel ashamed for paying a compulsory subscription for supervision by a statutory body with such a frail opinion of itself that it does nothing to encourage new entrants to its numbers.

By contrast our own 'trade union', the BDA, responded instantly with abundant printed material detailing how to become a dental technician or a dental therapist or a dental hygienist or a dental nurse, in addition to modestly listing dental surgery as a possible career choice.

If matters have deteriorated so greatly during my half century in our formerly esteemed profession, should we all be exhorted to hang our heads in shame and hide from the public gaze?

\section{B. Rothschild}

London

doi: 10.1038/sj.bdj.4810506

\section{Atkins diet dilemma}

Sir,- Over the last week I've seen two patients of previously good oral hygiene and minimal plaque who now have huge deposits of fresh calculus.

Both are ladies who have been on the Atkins diet for the last few months. One said that her teeth felt more 'slimy' and the other was sure that her oral health had been affected because of the lack of fibre 'to chew on' in her food. Has anybody else noticed this?

\section{B. Skinner}

London

doi: 10.1038/sj.bdj.4810507

\section{Antibiotic prophylaxis}

Sir,- I am writing in response to the article by Seymour et al. about the need for antibiotic prophylaxis for dental patients with joint prostheses (BDJ 2003; 194: 649653). On behalf of the BDA Formulary Committee, I welcome this useful article, which helps to inform the long-standing debate on this subject.

The Formulary Committee is currently having discussions with the British Orthopaedic Association in order to revise the guidance on antibiotic prophylaxis to both dentists and orthopaedic surgeons in the light of current evidence and

knowledge.

\section{S. Carruthers}

London

doi: 10.1038/sj.bdj.4810508

\section{Fixing the problem}

Sir,- As an orthodontist I rarely have to deal with an acute dental emergency. At $11.50 \mathrm{pm}$ one Sunday night a parent of a 16-year old I had never seen before telephoned.

His son had a bike accident three hours previously and had injured his nose and lip and avulsed UR1 (11).

He had attended casualty in a major teaching hospital but they were unable to do more than put the tooth back into its socket where it was completely loose. Attempts to access his dentist and other dental colleagues had proven fruitless, so in desperation they contacted the local orthodontist.

On examination, the nose and lip were badly swollen, and UR1 (11) was mobile and could not be pushed fully into its socket. Bearing in mind that displaced fractures are sometimes reduced by the application of sustained traction over a period of time, it was decided to use the same approach. Orthodontic brackets were bonded to UR1 (11), UL1 (21) and UL2 (22).

A highly flexible 014" nickel titanium sectional arch was fitted into the bracket slots of UR1 (11), UL2 (22) and under the slot of UL1 (21). In this way an apically directed force was applied to UL1 (21) .

Within 12 hours the tooth was fully back in the socket. He was referred to a maxillofacial surgeon regarding injuries to nose and lip, and to his regular dentist for continuing care. Although the use of orthodontic brackets for splinting is well known, this report also shows how a similar approach can be used to gradually fully re-seat an avulsed incisor into its socket.

\section{A. M. Cohen}

London

doi: $10.1038 /$ sj.bdj.4810509

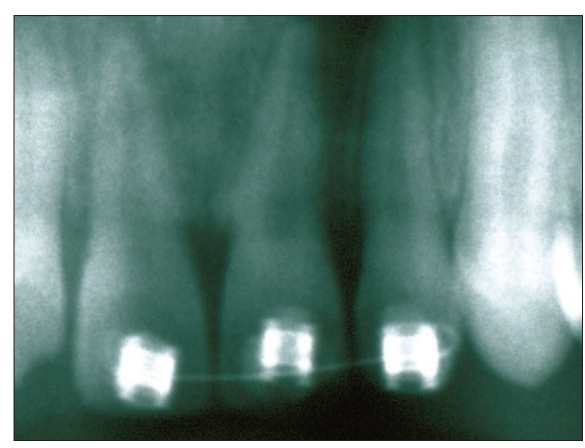

X-ray illustrating how the orthodontic brackets were used 